\title{
Papers
}

\section{Service charges in commercial property - Information on the new RICS Code of Practice}

Received (in revised form): 28 September 2006

\section{Geoffrey Silman}

has practiced as a property solicitor for 30 years, specialising in commercial landlord and tenant law with an emphasis on advising retailers on their acquisitions, disposals and management issues. He was co-founder of the firm Nathan, Silman, which had a reputation as a niche retail practice, and for the last five years has been a consultant at Finers Stephens Innocent following the merger of the two firms. He has written extensively for Estates Gazette, Retail Week, Property Law Journal and Property Week and has spoken at a workshop at the BCSC annual conference.

\begin{abstract}
Commercial service charges unlike residential are not subject to legislation so the lease contract and case law govern the position. There have been attempts to indicate good practice and more teeth will be added by the RICS Code which comes into force on 1 April 2007. This article details the main provisions and questions how much weight the Code will have. Hopefully it will not be an April Fool.
\end{abstract}

\section{Keywords:}

best practice, transparency, management, administration, technical support, enforcement

Journal of Retail and Leisure Property (2007) 6, 1-7.

doi:10.1057/palgrave.rlp.5100040

\section{INTRODUCTION}

The retail and leisure sector is probably more concerned about service charges in the commercial world than any other - or at least it ought to be. These outgoings often represent a significant part of the operator's premises overheads, particularly in shopping centres and can be worryingly unpredictable.

It is therefore perhaps surprising that, unlike the heavily regulated residential sector, there is no material legislation governing service charges in business leases and it is very much 'what you read is what you get'. This therefore illustrates how important negotiating the terms of a lease can be.

The main service charge regulations are often to be found at the end of

Geoffrey Silman

Finers Stephens Innocent, 179 Great Portland Street London $\mathrm{W}_{1} \mathrm{~W}_{5} \mathrm{LS}$, UK

Tel: + 4402073447659

Fax: + 4402073445605

E-mail: gsilman@fsilaw.co.uk the document - the Landlord and Tenant equivalent of a good day for burying bad news. The Landlord's solicitors might place these clauses on page 80 onwards on the assumption that the Tenant's solicitor will be so tired after reading the previous 79 that he or she will be off-guard and fail to appreciate that the red pen should be most liberally used at this stage to mitigate the potentially financially onerous provisions. 
It was commonly argued by Landlord's solicitors when faced with amendments to this part of the Lease that none could be accepted because of the need for uniformity in all the Leases in the development. This often had the desired effect but more commonly these days persistence pays off and every Lease in a scheme might therefore have subtle (and not so subtle) differences which in turn by definition means that one size does not fit all and so each Leassee should not assume that the standard service charge demands and accounts provided to each Tenant accurately reflects the individual Lease liability.

Certainly the more well-known and sizeable retailers scrutinise their service charge invoices much more carefully than used to be the case and by so doing often save themselves significant sums.

Ironically, the need for vigilance has increased even though Lease terms are shorter. Ideally and justifiably Tenants who only have short commitments should seek inclusive rents or capped service charges to reflect their limited interest in the premises. This is vital and the retailer should think seriously about walking away if the Landlord does not agree.

In an attempt to create greater harmony in this area between Landlord and Tenant, 10 years ago the first Guide to Good Practice was produced, was updated in 2000 and is now embodied in the Royal Institute of Chartered Surveyors (RICS) Code of Practice recently published ${ }^{1}$ but to take effect from 1 April 2007 (applicable in England and Wales only). It aims to identify 'Best Practice' and will supersede the Guide.

Although this Code is given greater clout than the previous Guide the fact cannot be escaped that, as it says, it 'is not intended to override existing leases'. Indeed, in leases coming into effect from 1 April 2007, the lease itself will still have the last word and there is no obligation to follow it.

Whilst the RICS steering group expects managers to emulate the Code and match their delivery as close as possible despite any lease constraints that might exist, there is no real sanction.

It could be argued that members of the RICS might incur some wrath from their professional body if the Code is blatantly ignored, but this remains to be seen. The introduction states that the Code for 'RICS members, has more prominence by virtue of its status as official RICS material. The Code supersedes the Guide and has the same status as a Guidance Note'. What does that mean? There is a health warning reading as follows: 'When an allegation of professional negligence is made against a practitioner, the Court is likely to take account of the contents of any relevant guidance notes in deciding whether or not the practitioner acted with reasonable competence'. However, two paragraphs further down it does say that 'it does not follow that a practitioner will be adjudged negligent if he or she has not followed the practices recommended in this code. ... where practitioners depart from the practice recommended in this note they should do so only for good reason. In the event of litigation, the Court may require them to explain why they decided not to adopt the recommended practice.' What is clear is that every practitioner should be up to date and aware of the contents of the Code and the penultimate paragraph of the Guidance Note says as much. 
There is a stick to beat recalcitrant practitioners but it might well break on impact rather the cause real hurt.

Even though the hope is that renewal leases will be brought up to the standard as set out in the Code, the introduction recognises that this will only be so far as is permitted by law and it will be interesting to see how case law evolves.

The road to service charge arrangements between Landlords and Tenants is paved with good intentions and best practice is stated to require services to be procured on a value for money basis and competitive quotations should be obtained for the supply of these services.

Furthermore the service charge is to be on a 'not for profit not for loss' basis and the costs must be transparent including management fees.

There is an obligation imposed by the Code that managers will issue budgets to occupiers with an explanatory commentary at least one month before the start of the service charge year with reconciliations following the year end to all users within four months thereafter.

Even if such time limits are specifically included within the lease, what happens if they are missed? The lease might include some specific sanction but this is unlikely to be accepted by a Landlord. However, by anology with a case on Rent Review, ${ }^{2}$ it might well be possible for a tenant to make time of the essence for the production of the year end reconciliations and if within a reasonable time thereafter they are still not forthcoming a court could decide that no excess for that year, if due, is payable.

Prompt notification of unforeseen variances of more than 2 per cent above RPI in the total annual spend must be made known to all occupiers with an explanation as to how it is to be mitigated.

The main body of The Code is divided into various headings as follows:

- Management

- Communications

- Transparency

- Service Standards and Provision

- Administration

- Additional Shopping Centre Services

Continuing the theme of best practice both owner and manager are to recognise a duty of care to each other with a right for occupiers to reasonably challenge the propriety of expenditure with each party bearing their own costs in so doing unless agreed or determined otherwise.

It should be the manager's duty to identify quarterly whether there are unforeseen variances in the budget and notify accordingly and to confirm the half yearly forecast on an unaudited basis. When major works are planned, tenants should be given a summary of details of the results of tenders and the processes gone through, together with full information on the programme of works, costs and the process to be adopted for keeping occupiers informed.

On account service charges should be held separately from other monies and any interest earned after deducting bank charges, tax and any other reasonable items, are to be credited back to the account. 
Contractors and suppliers of services will be required to perform according to written performance standards, which are set out in an Appendix to The Code and recoverable service charge costs are to be restricted to charges and associated administrative costs properly incurred by the owner in the operation or management of the property. Perhaps most importantly in paragraph 29 there is a specific list of items that will not be included. It is worth setting these out in full:

(a) Any initial costs (including leasing of initial equipment) incurred in relation to the original design and construction of the fabric, plant or equipment.

(b) Any setting up costs that are reasonably to be considered part of the original developments costs of the property.

(c) Improvement costs above the costs of normal maintenance, repair or replacement.

(d) Future redevelopment costs.

(e) Such costs which are matters between the owner and an individual occupier, for instance:

- enforcement of covenants for collection of rent;

- costs of letting units;

- consents for assignments;

- sub-letting;

- alterations;

- rent reviews;

- additional opening hours etc. and

(f) any costs arising out of the failure/negligence of the manager or owner.

It has in any event been fairly common practice for tenant's solicitors to incorporate their own list of items to be specifically excluded from the tenant service charge but sometimes more detailed than those listed in The Code. This should not therefore be considered a comprehensive schedule.

On a very sensitive subject, paragraph 30 states that service charge costs may include enhancement of the fabric, plant or equipment where such expenditure can be justified following the analysis of reasonable options and alternatives. Owners will provide the facts and figures to justify such a decision. This has probably been one of the greatest areas of dispute.

Whilst the general principle of owners keeping costs under review is incorporated, it does go on to say that contractors and suppliers should be required to submit competitive tenders or give competing quotations, perhaps every three years but if the parties are happy with the standards achieved to date, the owner should benchmark the prices.

Management fees for long have been a bone of contention. When they have been determined by reference to a percentage of the expenditure, as has often been the case, the natural reaction is that this acts as a total disincentive to keeping costs down. There have also been situations where the percentage has been levied on the VAT inclusive cost! The Code removes the percentage link on the basis that it is no longer appropriate 
and the price for the management services is to be a fixed fee for a reasonable period of time, possibly subject to indexing. There will be a need for the management service to be regularly tendered or benchmarked against the market.

Another area of long standing debate has been how the proportions each occupier contributes are calculated. Sometimes they are based on rateable value and other times on floor areas, which are sometimes weighted or on a fair and reasonable basis. There are within the Code detailed lists of those methods and apportionment schedules.

By requiring the schedule to be made available to all occupiers showing the total apportionment for each unit the theoretical (and occasional real) opportunity for a landlord to charge 11 occupiers 10 per cent each and thereby make a profit should be avoided. Although it should go without saying, the Code does say that the occupiers will not be charged towards the costs of unlet premises and the owner should meet the costs of any special concession to any one occupier (not applicable in the case of a properly constituted weighting formula).

It also makes clear that the owner will bear a fair proportion of costs attributable to his or her use of the property for example where an on-site management office is used in part as the owner's regional office.

Another area of dispute is the income generated from common parts, such as car parks, mobile phone masts, advertising or radio aerials. If the income is retained by the owner rather than being credited to the service charge account, the costs associated with the operation of those centres should not be allocated to the service charge account.

The detail to be incorporated in budgets and certified accounts are set out to make them easily understood and transparent.

In particular, the accounts are required to give a full summary of the items of expenditure and detailed explanation of any material variations from the budget.

The budgets and accounts should be accompanied by a report giving the following minimum information:

(a) the reasonably comprehensible level of detail to enable occupiers to compare expenditure against estimated budget;

(b) explanations of significant individual costs and of variances from the previous years budget/accounts;

(c) comparison against the previous two years actual costs where appropriate;

(d) information on core matters critical to that account (eg levels of apportionment, contracts, report on tendering etc);

(e) the achieved and/or targeted measures of improved management performance (eg successes in delivering improved quality services and greater value for money);

(f) separately identified on-site management team costs;

(g) details and results of the last previous and forthcoming tendering exercise (occupiers will be advised of the contractors who are providing the services); and

(h) a statement detailing how income generated from operating the property (sometimes known as 'commercialisation' or 'mall income') 
is dealt with and how shared services are charged setting out how they impact with the service charge and what reimbursement has been made to the service charge for these.

Owners are to allow occupiers a reasonable period (eg four months from issue) in which to raise enquiries in respect of the certified accounts and should deal with reasonable enquiries promptly and efficiently. A charge can be levied for supplying supporting documentation. An occupier can request an independent audit and the owner should agree provided the occupier pays.

Where there is a change of owner or agent, within no more than four months following completion of any sale the Seller will be required to provide the Buyer with full details of all expenditure, accruals and prepayments for the outstanding years up to the date of sale.

The Code deals with the somewhat difficult area of sinking and reserve funds which are to be held in an interest bearing account in trust for the occupiers, separate from the owners own monies and the owner will be required to make all payments into these funds for any void premises. As previously stated the interest earned and late payment interest should be credited to the service charge account. Care needs to be taken, particularly in the drafting of the lease as to where the money is held and who owns it, particularly to cover any situation of liquidation.

The paragraph dealing with additional shopping centre services focuses on marketing and promotions, which are recognised as a shared cost to be borne by both owners and occupiers resulting from essential consultation.

The final section of the Code (apart from the Appendices which give examples of inter alia, what is considered best practice and illustrations of how some of the principles outlined in the Code can be achieved) deals with what is described as technical support. The sub-headings are:

- Performance contracts

- Initial provision, improvement and refurbishment of equipment

- Treatment of non-core income

- Common method of apportionment

- Apportionment schedules

- Sinking and reserve funds

- Cost code analysis

- Dispute resolution

- Management charges

In part these amplify what has gone before. Performance contracts are described as a contracting methodology designed to meet the specific needs set down by the user and where achievement against set performance standards can be measured and reflected in the cost incurred for the level of service actually provided. By specifying standards to be achieved, the contractor is required to ensure the most cost-effective processes and procedures, thus achieving value for money.

It is made clear that the initial cost of providing furniture and facilities will not be included as part of the service charge and debate is encouraged as to how the costs of any improvements to existing 
equipment are to be levied. Refurbishment is distinguished from improvement and as a general guide where the former result in higher rental values, costs are usually to be the owners responsibility. What happens with innovation where, for example, a new CCTV system is installed? It might be reasonable to recover those costs because they should result in a decrease in manned security costs but once again, as with everything, the contract between the landlord and the tenant as stated in the lease will be decisive unless there is ambiguity. The sections on non-core income and apportionment, as previously stated, expand upon the views expressed in the main body of the Code and sinking funds and reserve funds are differentiated by explaining that the former is a replacement fund where the owner builds up a fund to pay for the repair and replacement of major items of plant and equipment and the latter is a fund built up to equalise expenditure with regularly recurring service items to avoid fluctuations in the amount of service charge payable each year. However, it is acknowledged that whichever is adopted they create potentially complicated tax and administrative issues and have become rarer.

The RICS intends that the Code provides access to alternative dispute resolution.

It remains to be seen how much of the Code is incorporated into new leases. However, it is to be hoped that even where it is not and nothing in the lease conflicts with it, in practice much will be adopted, and will become the norm, certainly so far as the administration of the Service Charge is concerned. The concern remains that many leases will still conflict with the Code either through ignorance or because by virtue of the strength of their respective negotiating positions the parties insist that material variations from it are incorporated in their contractual document.

\section{References}

1. Royal Institute of Chartered Surveyors (2006). RICS Code of practice for service charges in commercial property (England and Wales), available from http://www.rics.org/Property/ Commercialproperty/Commerciallandlordandtenant/Commercialservicecharges/, accessed 28th September 2006.

2. Barclays Bank plc v Savile Estates Ltd (2002). EWCA Civ 589. 